\title{
RBE of "Prometeus" Facility Protons for Irradiation of Tumor Cells in vitro with One and Three Fields
}

\section{Nasedkina N. V. ${ }^{1,2}$, Beketov E. E. ${ }^{1}$, Isaeva E. V. ${ }^{1}$, Malakhov E. P. ${ }^{1}$, Golovanova 0. Y. ${ }^{1}$, Ulyanenko L. N. ${ }^{1}$, Chernukha A. E. ${ }^{1}$, Saburov V. 0. ${ }^{1}$, Lepilina 0. G. ${ }^{1}$, and Ulyanenko S. E. ${ }^{1}$}

${ }^{1} \mathrm{~A}$. Tsyb Medical Radiological Research Center - branch of the National Medical Research Center for Radiology of the Ministry of Health of the Russian Federation ${ }^{2}$ Obninsk Institute for Nuclear Power Engineering of the National Research Nuclear University MEPhl, Studgorodok 1, Obninsk, Kaluga region, 249040, Russia

\section{Abstract}

The study was aimed to the biological effectiveness of the proton scanning beam of the first Russian medical facility. The clonogenic assay of B-16 tumor cells was used as a test system. Cell irradiation was carried out in a suspension condition in a water

Corresponding Author:

Beketov E. E.

beketov.ee@yandex.ru

Received: 23 December 2017

Accepted: 15 January 2018

Published: 21 February 2018

Publishing services provided by

Knowledge $\mathrm{E}$

(c) Nasedkina N. V. et al. This article is distributed under the terms of the Creative Commons

Attribution License, which permits unrestricted use and redistribution provided that the original author and source are credited.

Selection and Peer-review under the responsibility of the AtomFuture Conference Committee.

\section{G OPEN ACCESS}

phantom. Single and three-field exposures were studied. The dose interval was 2-8 Gy. The energy range from 47.5 to $92.0 \mathrm{MeV}$ was used for the Bragg peak formation. The relative biological effectiveness of protons comparing to gamma-rays was 1.2 for single-field and 1.5 for three-field irradiation. The results obtained agree with literature data related to the used cell culture (B-16) and linear energy transfer range $(3 \div 8 \mathrm{keV} / \mu \mathrm{m})$.

Keywords: oncology, proton therapy, SOBP, a scanning beam, clonogenic assay, RBE.

\section{Introduction}

The prospect of the clinical application of high-energy protons was first suggested by Robert Wilson in 1946, and the first patients were treated with a proton beam at the Berkeley Laboratory of Radiation Research in California in the early 1950s [7]. Currently in the world (excluding Russia) there are 62 proton therapy centers in operation, located in 17 countries (USA, Japan, Germany, Italy, China, France, Austria, etc.) [16]. According to the forecasts, its number will increase in the next few years [18]. Up to day 130000 patients have been treated with protons.

From the point of view of radiotherapy, the key feature of protons, as well as other heavy charged particles, is the specific distribution of the absorbed dose. The increase in energy losses at the end of the particle track within the biological tissue results in 
formation of the Bragg peak, the place where the tissue receives the maximal dose. The position of this peak depends on the energy of the particles. Thus, if the proton beam contains particles with different but defined energies, it is possible to irradiate a given volume in the same dose using spread-out Bragg peak (SOBP).

A number of studies, including recent ones, have shown that the value of the relative biological efficiency (RBE) is not constant and depends on the initial beam energy, the linear energy transfer (LET) associated with it, the dose per fraction, the position in SOBP, tissue radiosensitivity ( $\alpha / \beta$ ratio) and biological effect estimation method $[3,6$, $9-15,17]$.

In Russia, up to the present day, three centers of proton therapy are in operation: in Dubna (JINR), St. Petersburg (PNPI) and from 2016 in A. Tsyb Medical Radiological Research Center (MRRC). The source of a proton pencil scanning beam in MRRC was developed by ZAO "Protom". The proton therapy center in MRRC could be considered as the first Russian medical facility.

The purpose of this study was to determine the RBE of the "Prometheus" installation proton beam in experiments on the culture of melanoma cells B-16 in case of single and three-field irradiation.

\section{Materials and Methods}

\subsection{B-16 cells}

The biological object used in the study was the culture of mouse melanoma cells B16F10. The characteristic of the cell line is given in the previously published work of the authors [2]. The culture was grown in a monolayer condition in culture flasks with a surface area of $25 \mathrm{~cm}^{2}$ (Corning, USA) in RPMI-1640 medium (PanEco, Russia) with addition of $10 \%$ fetal bovine serum (Biosera, France) and $0.01 \mathrm{mg} / \mathrm{ml}$ gentamicin (PanEco, Russia). The cells were cultured in a $\mathrm{CO}_{2}$ incubator (MCO-5AC, Sanyo, Japan) at $+37^{\circ} \mathrm{C}$ and $5 \% \mathrm{CO}_{2}$.

On the day of the experiment, the cells were removed from the plastic with a mixture of versen (0.02\%, PanEco, Russia) and trypsin (0.25\%, PanEco, Russia) in 1:1 ratio. Then the cells were resuspended in RPMI-1640 medium containing $10 \%$ of serum. The cells were counted using hemocytometer and diluted to the appropriate concentration (300-600 thousand in $1 \mathrm{ml}$ ). For irradiation, the cell suspension was dispensed into micro centrifuge tubes (volume $1.5 \mathrm{ml}$, Genfollower, China) up to $1.3 \mathrm{ml}$. Before and 
after irradiation, the cells were kept on ice. The irradiation was carried out at room temperature.

\subsection{Clonogenic assay}

After the irradiation, the clonogenic activity of the cells was determined. For this, the cells were resuspended, diluted to the proper concentration and plated (1000 to 72,000 cells per dish, depending on the dose of irradiation) in $100 \mathrm{~mm}$ Petri dishes (Corning, USA) with medium RPMI-1640 supplemented with $10 \%$ of fetal bovine serum. The cells were incubated in a $\mathrm{CO}_{2}$ incubator for 7-8 days before the formation of visible colonies. After the incubation, the culture medium was removed; the colonies were stained with a $2 \%$ solution of methylene blue in $50 \%$ ethanol. Colony counting was conducted using Scan 100 counter (Interscience, France). The clonogenic cell fraction was expressed as a ratio to the number of seeded cells and adjusted to the survival of the cells in the control.

\subsection{Source of protons}

Irradiation was carried out at the "Prometeus" installation (protons acceleration is performed by the synchrotron, the beam output - horizontal) in the water phantom. The distance from the front wall of the phantom to the source was $70 \mathrm{~cm}$. Verification of the phantom position was carried out from two directions (o and 90 degrees). The location of the phantom on the object table of the positioning system is shown in Fig. 1. A tube with a cell suspension after shaking ( $\mathrm{V}-1$ Plus, Biosan, Latvia) was placed in the central port of the water phantom.

Proton irradiation was conducted with single and three fields $\left(0,90\right.$ and $180^{\circ}$ ). Before the experiments, an irradiation plan was calculated. The dose of irradiation was $2 \mathrm{~Gy}$. The volume of PTV (Planning Target Volume) was $24.2 \mathrm{~cm}^{3}$ for irradiation from one field and $18.5 \mathrm{~cm}^{3}$ in case of three fields. Doses of 2, 4, 6 and 8 Gy were used for irradiation. The same irradiation plan was repeated 2, 3 and 4 times was used. The pause between the fractions did not exceed $10 \mathrm{~s}$ for single filed irradiation and $20 \mathrm{~s}-$ in case of three-field exposure. The average dose rate (for the time from the start of irradiation to the system signal of its end) for one field was $2.2 \mathrm{~Gy} / \mathrm{min}$, for three fields $-0.84 \mathrm{~Gy} / \mathrm{min}$. 


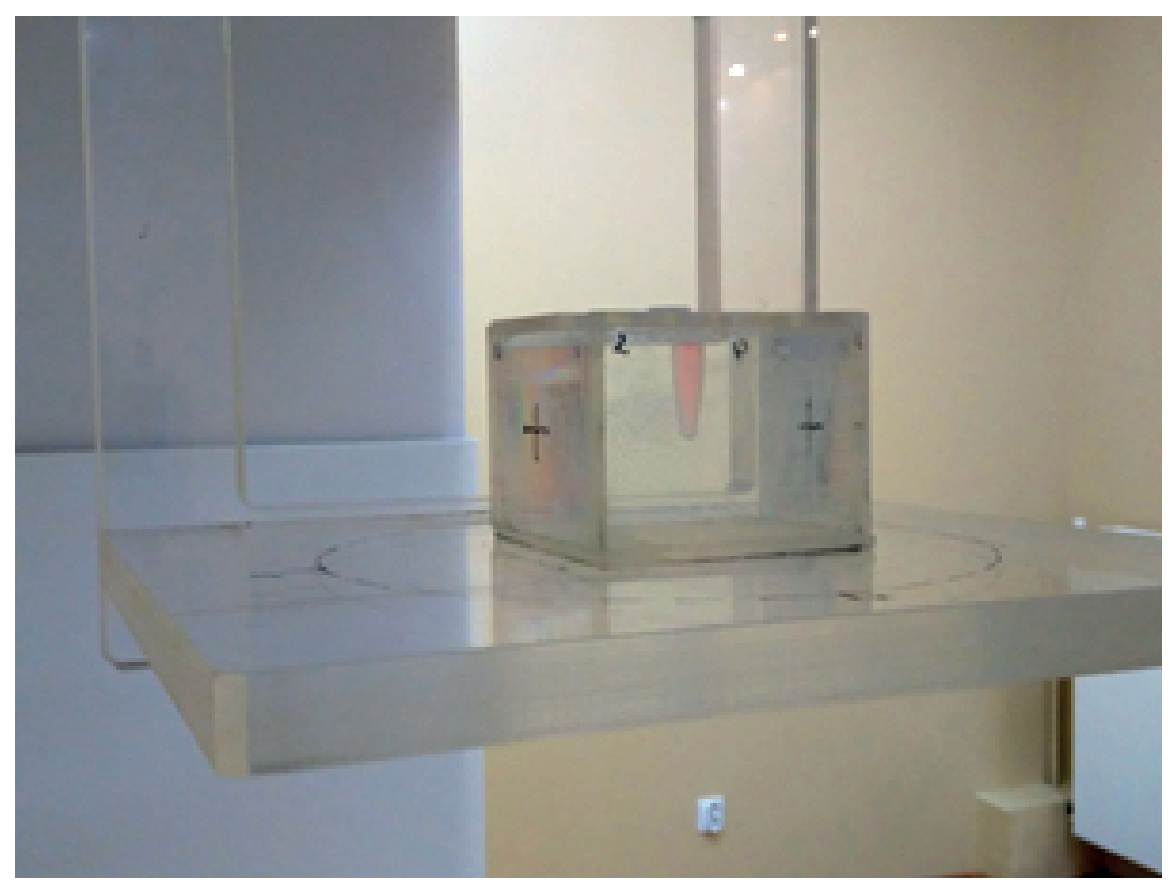

Figure 1: Water phantom with a test object on the table of the positioning system.

\subsection{The source of photons}

The standard radiation was the $\mathrm{\gamma}$-rays of ${ }^{60} \mathrm{Co}$ with average energy $1.25 \mathrm{MeV}$. The dose rate was $1 \mathrm{~Gy} / \mathrm{min}$. The doses of exposure were $2,4,6,8,10 \mathrm{~Gy}$. The tubes with the cell suspension after shaking were irradiated without phantom.

\subsection{Statistics}

Biological experiments were performed in 4 replicates. The received data of cell survival processed using statistical software R 3.4.1 and Veusz 2.0.1.

Dose dependency fitting was conducted using linear-quadratic model (1). Conformity of experimental data to the model was evaluated by $x^{2}$ criterion.

$$
S=100 \cdot \exp \left(-\alpha \cdot x-\beta \cdot x^{2}\right)
$$

Dose measurement error for protons and photons according to documentation was within $5 \%$. The true error of the absolute survival values was $12 \%$; the error of the RBE estimation according to the linear-quadratic model was $10 \%$. 


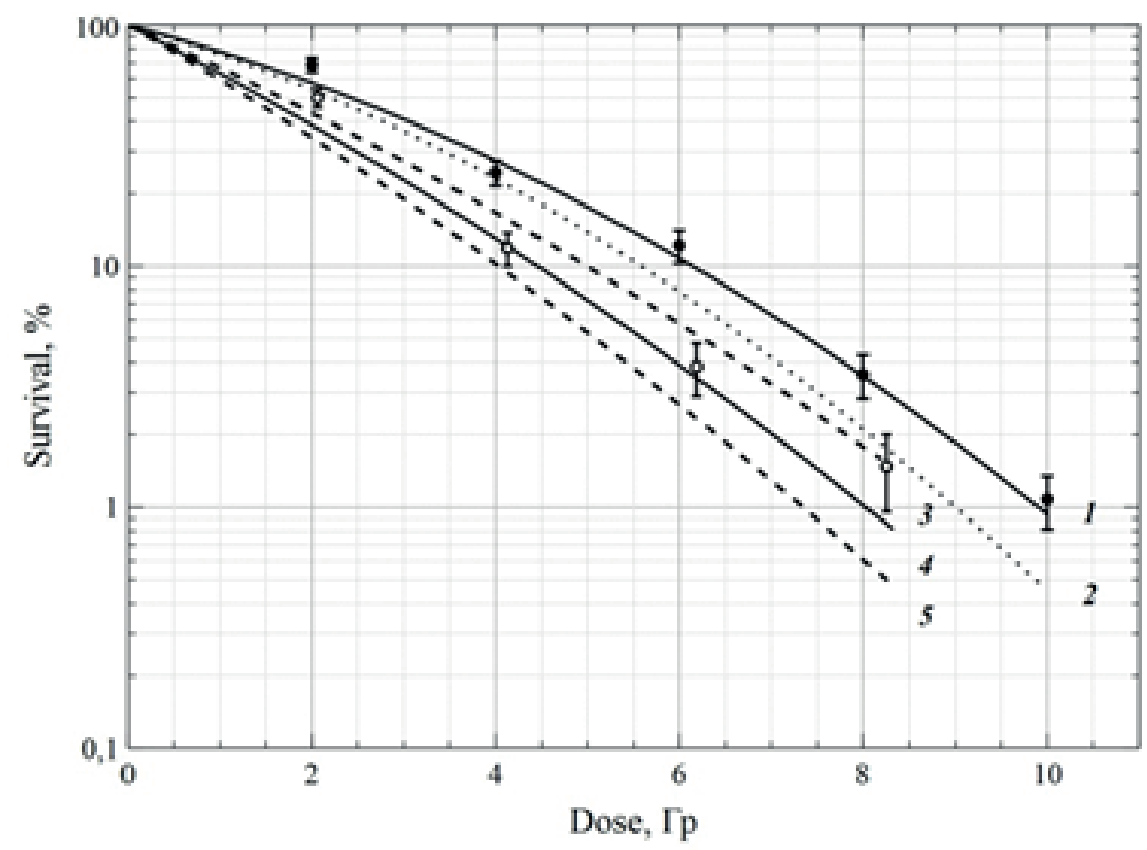

Figure 2: Dependence of B-16 cells survival according to its clonogenic activity on the dose: $1-\gamma$-irradiation (closed symbols), 2 - theoretically expected survival curve after proton irradiation, 3 - protons in singlefield irradiation, 4 - combined data on protons (open symbols), 5 - protons in three-field irradiation.

\section{Results}

Dose dependences of clonogenic activity of murine melanoma B-16 cells after irradiation with protons and gamma radiation are shown on Fig. 2.

Figure 2 shows that the curves of protons are located below the $\mathrm{\gamma}$-ray curve and theoretically expected for protons due to the higher biological efficacy. Irradiation from three directions was more effective than with one due to more complex LET distribution and more uniform dose distribution. The value of the LET of protons was within 3-8 keV/ $\mu \mathrm{m}$; in case of gamma-rays $-0.3 \mathrm{keV} / \mu \mathrm{m}$. The RBE was higher than generally accepted 1.1 value both for irradiation from one and three directions: at the level of $10 \%$ survival the RBE is 1.2 for one field irradiation and 1.5 in case of three fields.

\section{Discussion}

The studies of biological effectiveness of protons continue for a long time, but there is no certain answer about the RBE issue. According to T. Friedrich et al. data [4] obtained for the most frequently used cell cultures, the RBE of protons for of $10 \%$ survival in the range of LET values of $3 \div 8 \mathrm{keV} / \mu \mathrm{m}$ varies from 0.95 to 1.47 . 


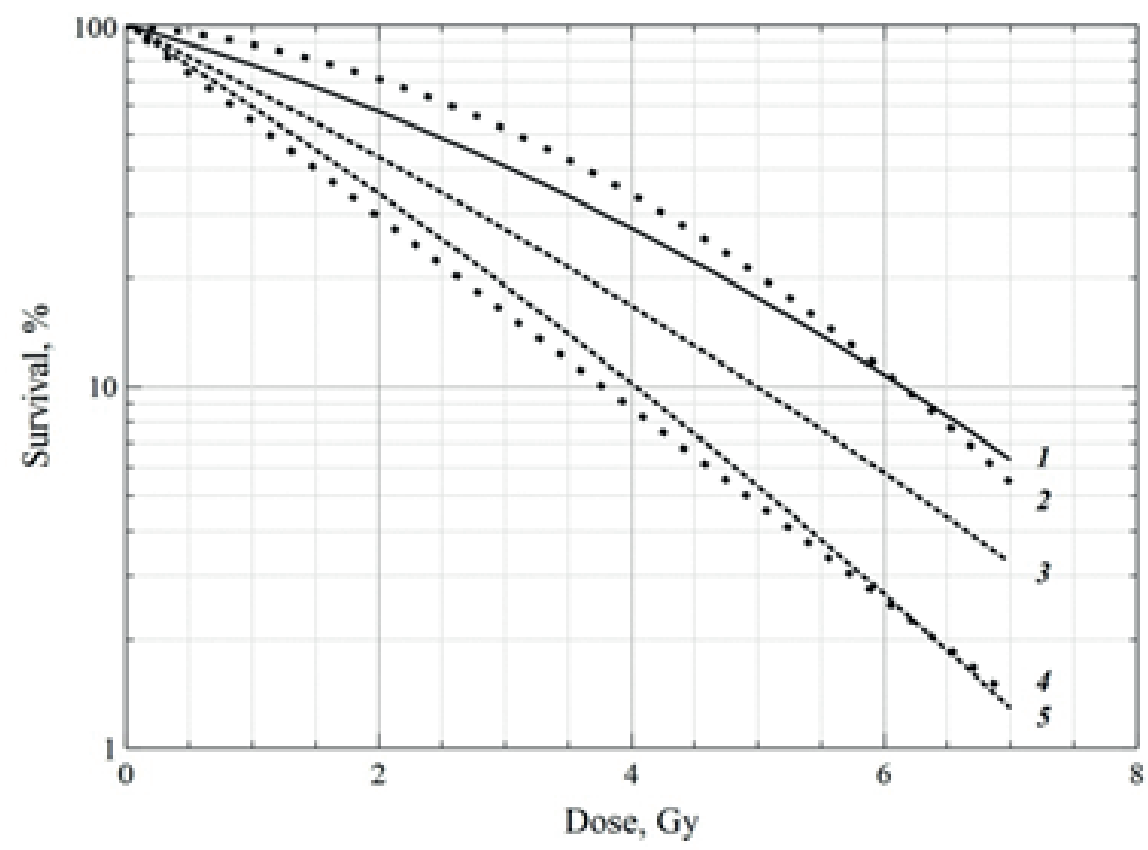

Figure 3: Dose dependence of the survival of B-16 melanoma cells: $1-\gamma$-irradiation, 2-protons on the plateau according to Ibanez et al. [8], 3 - protons in single-field irradiation, 4 - protons in the Bragg peak according to Ibanez et al. [8], 5 - protons in three-field irradiation.

In studies conducted by I. Ibanez et al. [8] the RBE value of protons at a $10 \%$ survival of melanoma B16 cells was 1.0 in the plateau region (LET $-3.4 \mathrm{keV} / \mu \mathrm{m}$ ), and 1.6 in the Bragg peak (LET - $14 \mathrm{keV} / \mu \mathrm{m})$. Since in our study the LET value varied from 3 to 8 $\mathrm{keV} / \mu \mathrm{m}$, we could assume that our data coincided with the results of I. Ibanez et al. (Fig. 3).

With the use of scanning proton beams, the LET variations could be extremely high due to the intensity modulation [6]. In case of irradiation with several directions (fields) further complications in the regions of high average LET may arise [5]. If the longrun objective is the assessment of RBE to select the patient exposure scheme, the main task is to find a balance between this uncertainty and the clinical relevance in correcting RBE values.

\section{Conclusion}

To date, studies on assessment of proton biological effectiveness has been mainly carried out using passive scattering techniques, and a small amount of data is available for pencil scanning beams. The results of our studies show that the experimental RBE value of protons differs from the recommended 1.1 by the International Commission on Radiation Units and Measurements 1.1. 


\section{Funding}

This work was carried out within the framework of the state task of A. Tsyb MRRC branch of the National Medical Research Center for Radiology of the Ministry of Health of the Russian Federation in 2015-2017 [1].

\section{Acknowledgments}

The authors are grateful to employees of the MRRC proton therapy center for the invaluable help in carrying out this research.

\section{References}

[1] Kaprin A.D., Galkin V.N., Zhavoronkov L.P., et al. Synthesis of fundamental and applied research is the basis for ensuring a high level of scientific results and their introduction into medical practice.// Radiation and Risk. - 2017. - T. 26. -N. 2. - P. 26-40.

[2] Beketov E., Isaeva E., Koryakin S., et al. The study of biological effectiveness of U70 accelerator carbon ions using melanoma B-16 clonogenic assay. // Rad. Applic. - 2017. - V. 2. - I. 2. - P.90-93.

[3] Cuaron J.J, Chang C., Lovelock M., et al. Exponential increase in relative biological effectiveness along distal edge of a proton Bragg peak as measured by deoxyribonucleic acid double-strand breaks. // Int J Radiat Oncol Biol Phys. - 2016. - V.95. - I.1. $-P .62-69$.

[4] Friedrich T., Scholz U., Elsässer T., et al. Systematic analysis of RBE and related quantities using a database of cell survival experiments with ion beam irradiation. // J Radiat Res. - 2013. - 54. - I. 3. - P. 494-514.

[5] Giovannini G., Bohlen T., Cabal G., et al. Variable RBE in proton therapy: comparison of different model predictions and their influence on clinical-like scenarios. // Radiat Oncol. -2016. - V.11. - P. 68.

[6] Grassberger C, Paganetti H. Varying relative biological effectiveness in proton therapy: knowledge gaps versus clinical significance.// Acta Oncol. -2017. - V.56. - I.6. - P.761-762.

[7] Hall E. Protons for radiotherapy: a 1946 proposal.//Lancet Oncol. -2009. - V.10. - I.2. -P.196. 
[8] Ibanez I., Bracalente C., Molinari B., et al. Induction and Rejoining of DNA Double Strand Breaks Assessed by H2AX Phosphorylation in Melanoma Cells Irradiated with Proton and Lithium Beams. // Int J Radiat Oncol Biol Phys. -2009. - V.74. - I. 4. - P. 1226-1235.

[9] Jones B. Towards achieving the full clinical potential of proton therapy by inclusion of LET and RBE models. Cancers (Basel). - 2015. - V.7. - I.1. -P.460-480.

[10] Keta O., Todorovic D., Popovic N., et al. Radiosensitivity of human ovarian carcinoma and melanoma cells to $y$-rays and proton. // Arch Med Sci. - 2014. - V.10. - I.3. P. 578-586.

[11] Maeda K., Yasui H., Matsuura T., et al. Evaluation of the relative biological effectiveness of spot-scanning proton irradiation in vitro. // J Radiat Res. - 2016. - V.57. - I.3. - P.307-311.

[12] Marshall T.I., Chaudhary P., Michaelidesova A., et al. Investigating the implications of a variable RBE on proton dose fractionation across a clinical pencil beam scanned spread-out Bragg peak. // Int J Radiat Oncol Biol Phys. - 2016. - V.95. - I.1. - P.70-77.

[13] Matsumoto Y., Matsuura T., Wada M., et al. Enhanced radiobiological effects at the distal end of a clinical proton beam: in vitro study. // Journal of Radiation Research.2014. - V.55. - I. 4. -P.816-822.

[14] Michaelidesova A., Vachelova J., Puchalska M., et al. Relative biological effectiveness in a proton spread-out Bragg peak formed by pencil beam scanning mode. // Australas Phys Eng Sci Med. - 2017. - V.40. - I. 2. -P.359-368.

[15] Paganetti H. Relative biological effectiveness (RBE) values for proton beam therapy. Variations as a function of biological endpoints, dose, and linear energy transfer. // Phys Med Biol. - 2014. - V.59. - I.22. - P.4194-4272.

[16] Particle Therapy Centers [Internet]. Particle Therapy Co-Operative Group [cited 2017 Nov 3]. Available from: https://www.ptcog.ch/.

[17] Slonina D., Biesaga B., Swakon J., et al. Relative biological effectiveness of the 60$\mathrm{MeV}$ therapeutic proton beam at the Institute of Nuclear Physics (IFJ PAN) in Krakow, Poland. // Radiat Environ Biophys. - 2014. - V.53. - I.4. - P.745-754.

[18] Tommasino F, Durante M. Proton Radiobiology. // Cancers. - 2015. - V.7. -P.353-381. 